\title{
Adaptive transgenerational plasticity in plants: case studies, mechanisms, and implications for natural populations
}

\author{
Jacob J. Herman and Sonia E. Sultan* \\ Biology Department, Wesleyan University, Middletown, CT, USA
}

\section{Edited by:}

Igor Kovalchuk, University of

Lethbridge, Canada

Reviewed by:

Igor Kovalchuk, University of Lethbridge, Canada

Carlos M. Herrera, Consejo Superior de Investigaciones Cientificas, Spain

${ }^{*}$ Correspondence:

Sonia E. Sultan, Biology Department,

Wesleyan University, Lawn Avenue,

Middletown, CT 06459, USA.

e-mail:sesultan@wesleyan.edu

\begin{abstract}
Plants respond to environmental conditions not only by plastic changes to their own development and physiology, but also by altering the phenotypes expressed by their offspring. This transgenerational plasticity was initially considered to entail only negative effects of stressful parental environments, such as production of smaller seeds by resource- or temperature-stressed parent plants, and was therefore viewed as environmental noise. Recent evolutionary ecology studies have shown that in some cases, these inherited environmental effects can include specific growth adjustments that are functionally adaptive to the parental conditions that induced them, which can range from contrasting states of controlled laboratory environments to the complex habitat variation encountered by natural plant populations. Preliminary findings suggest that adaptive transgenerational effects can be transmitted by means of diverse mechanisms including changes to seed provisioning and biochemistry, and epigenetic modifications such as DNA methylation that can persist across multiple generations. These non-genetically inherited adaptations can influence the ecological breadth and evolutionary dynamics of plant taxa and promote the spread of invasive plants. Interdisciplinary studies that join mechanistic and evolutionary ecology approaches will be an important source of future insights.
\end{abstract}

Keywords: maternal effects, seed provisioning, seedling development, epigenetics, DNA methylation

\section{INTRODUCTION}

Effects of parental (usually maternal) environmental stress on the size and development of plant offspring have been well known for several decades. Quantitative geneticists concerned with plant breeding as well as evolutionary biologists studying change by natural selection considered these inherited induced effects to be "a frequent, and often troublesome source of environmental resemblance" (Falconer, 1981) that masked the genetically inherited variants that were their central focus ${ }^{1}$. This view of transgenerational environmental effects as a nuisance led researchers to design experiments that minimized the likelihood of detecting these effects, which were treated as experimental error. This approach began to shift in the late 1980s and 1990s, when a series of seminal reviews and empirical investigations re-conceptualized these effects as a transgenerational form of individual phenotypic plasticity, and hence a potential source of ecologically and evolutionarily meaningful variation (Roach and Wulff, 1987; Schmitt et al., 1992; Sultan, 1996; Donohue and Schmitt, 1998; for overviews of both plant and animal studies, see Mousseau and Fox, 1998). Central to this new understanding was the recognition that parent individuals alter specific developmental traits in their progeny in response to particular environmental stresses, and that these alterations may enhance offspring growth and success under those same stresses.

\footnotetext{
${ }^{1}$ We use the term inherited in its inclusive sense, to indicate all effects transmitted from parent plant to offspring, i.e., effects of parental environment, parental alleles, or epialleles (see Danchin et al., 2011).
}

Such adaptive transgenerational plasticity is predicted to evolve in cases when the parental environment reliably predicts the offspring environment - e.g., when the offspring are likely to encounter the same specific stresses as the parent(s) (Agrawal et al., 1999; Galloway, 2005).

The past two decades have also seen extraordinary new insights to heritable epigenetic effects on gene expression, particularly the effects of DNA methylation patterns (Grant-Downton and Dickinson, 2005; Henderson and Jacobsen, 2007; Hauser et al., 2011). Although epigenetic mechanisms are a likely means of transmitting environmental effects across generations (Jablonka and Lamb, 1995) and may well be the basis for many cases of adaptive transgenerational plasticity (Rossiter, 1996; Bossdorf et al., 2008), mechanistic studies of epigenetic inheritance and ecological research on transgenerational plasticity have largely proceeded in isolation. As research interest in both epigenetic inheritance mechanisms and adaptive transgenerational plasticity has continued to surge (Jablonka and Raz, 2009; Mousseau et al., 2009), integrating these exciting areas promises important advances.

Here we review recent examples of adaptive transgenerational plasticity in plants in response to various environmental stresses, leading to a multi-species case study in the genus Polygonum that illustrates several fundamental points about this aspect of individual environmental response. We then provide a brief overview of the diverse mechanisms that mediate these fascinating responses, and conclude by highlighting some key ecological and evolutionary implications. 


\section{ADAPTIVE TRANSGENERATIONAL PLASTICITY: A BRIEF REVIEW}

Despite intense interest in functionally adaptive transgenerational effects in plants, to date only a limited number of studies fully document such effects (Donohue and Schmitt, 1998; Dyer et al., 2010; see Table 1). In part this reflects the particular design challenges of such studies, which must (a) raise genetic replicate parent individuals in contrasting environments (to test for effects of parent environment by holding genotype constant), and (b) monitor expression of ecologically important traits in offspring grown over one or more generations, to test for an adaptive match between parental conditions and offspring performance in like conditions. Below we discuss findings from a number of studies that meet these criteria.

Temperature stress is an environmental challenge that plants often confront in natural populations, and one likely to become even more prevalent as global climate change advances. Whittle et al. (2009) reported evidence for adaptive transgenerational responses to heat stress in Arabidopsis thaliana that persisted over at least two generations. Using a set of homozygous inbred lines, Whittle et al. (2009) found that $\mathrm{F}_{3}$ Arabidopsis progeny increased reproductive output fivefold under heat stress $\left(30^{\circ} \mathrm{C}\right)$ if the $\mathrm{F}_{0}$ and $\mathrm{F}_{1}$ generations had also experienced heat stress. This effect persisted into the $\mathrm{F}_{3}$ generation, even when $\mathrm{F}_{2}$ plants were grown at a moderate temperature $\left(23^{\circ} \mathrm{C}\right.$; Whittle et al., 2009). However, the precise functional and/or developmental changes to offspring that led to this fitness increase were not documented.

The effects of temperature stress also appear to be heritable and potentially adaptive in the cosmopolitan weed Plantago lanceolata. Two research findings in this system are particularly intriguing. First, the effects of cold temperature treatment persisted across two generations, significantly enhancing seed weight as well as fitness-related leaf and life-history traits in adult grandchild plants (Case et al., 1996). This result makes clear that the expression of transgenerational effects may not be confined to the seedling stage, as is often assumed. (Indeed, adaptive transgenerational effects are differently expressed in the second year of offspring life in this perennial weed; Latzel and Klimešová, 2010). Second, paternal temperature treatment also significantly affected offspring traits via interactions with the maternal temperature environment (Lacey, 1996). Although most cases of transgenerational plasticity are mediated by the maternal plant, and it is likely that direct maternal adjustments are of greatest magnitude, effects of paternal environment may also be relevant in outcrossing species (Roach and Wulff, 1987; Mazer and Gorchov, 1996; Diggle et al., 2010).

Edaphic stresses have been shown to elicit adaptive transgenerational responses in several model systems. Single-factor studies

Table 1 | Examples of adaptive transgenerational plasticity.

\begin{tabular}{|c|c|c|c|c|}
\hline $\begin{array}{l}\text { Parental } \\
\text { environment }\end{array}$ & Species & Offspring trait affected & $\begin{array}{l}\text { Number of } \\
\text { generations } \\
\text { inherited }\end{array}$ & Citation \\
\hline High temperature & Arabidopsis thaliana & Fruit and seed production & 2 & Whittle et al. (2009) \\
\hline Low temperature & Plantago lanceolata & Seed mass; probability of flowering; leaf area & 2 & Case et al. (1996), Lacey (1996) \\
\hline Nutrient deficiency & Oryza sativa & Biomass; plant height & 2 & Kou et al. (2011) \\
\hline Nutrient deficiency & Plantago lanceolata & Leaf biomass & 1 & Latzel et al. (2010) \\
\hline Nutrient deficiency & Polygonum persicaria & Root allocation & 1 & Sultan (1996) \\
\hline High salinity & Arabidopsis thaliana & Germination; seedling growth & 1 & Boyko et al. (2010) \\
\hline Drought & Polygonum persicaria & $\begin{array}{l}\text { Biomass; root length, depth, and extension } \\
\text { rate; seed provisioning; germination }\end{array}$ & 1 & $\begin{array}{l}\text { Sultan (1996, 2001), Sultan et al. } \\
\text { (2009) }\end{array}$ \\
\hline Serpentine soil & Aegilops triuncialis & Shoot biomass; phenology & 1 & Dyer et al. (2010) \\
\hline $\begin{array}{l}\text { Disturbance (mediated by } \\
\text { nutrient environment) }\end{array}$ & Plantago lanceolata & Shoot biomass & 1 & Latzel et al. (2010) \\
\hline Shade & Plantago lanceolata & $\begin{array}{l}\text { Cumulative fitness of maternal and offspring } \\
\text { generations }\end{array}$ & 1 & Donohue and Schmitt (1998) \\
\hline Shade & Polygonum hydropiper & $\begin{array}{l}\text { Seed provisioning; timing/amount of leaves } \\
\text { produced; biomass }\end{array}$ & 1 & Lundgren and Sultan (2005) \\
\hline Light habitat & $\begin{array}{l}\text { Campanulastrum } \\
\text { americanum }\end{array}$ & $\begin{array}{l}\text { Germination; seed mass; seedling survival; } \\
\text { leaf area; life-history }\end{array}$ & 1 & $\begin{array}{l}\text { Galloway and Etterson (2007, } \\
\text { 2009) }\end{array}$ \\
\hline Herbivory & $\begin{array}{l}\text { Raphanus } \\
\text { raphanistrum }\end{array}$ & $\begin{array}{l}\text { Seed mass; seedling growth; leaf trichome } \\
\text { density }\end{array}$ & 1 & $\begin{array}{l}\text { Agrawal et al. (1999), Agrawal } \\
(2001,2002)\end{array}$ \\
\hline Simulated herbivory & Mimulus guttatus & Leaf trichome density & 1 & $\begin{array}{l}\text { Holeski (2007), Scoville et al. } \\
\text { (2011) }\end{array}$ \\
\hline Herbivory & Impatiens capensis & Emergence; flowering; plant height; biomass & 1 & Steets and Ashman (2010) \\
\hline Viral infection & Nicotiana tabacum & $\begin{array}{l}\text { Pathogen resistance; homologous } \\
\text { recombination frequency }\end{array}$ & 1 & $\begin{array}{l}\text { Boyko et al. (2007), Kathiria et al. } \\
\text { (2010) }\end{array}$ \\
\hline Seasonal environments & Arabidopsis thaliana & Germination timing; life-history schedule & 1 & $\begin{array}{l}\text { Donohue et al. (2005), Donohue } \\
\text { (2009) }\end{array}$ \\
\hline
\end{tabular}


in rice (Oryza spp.) and Arabidopsis indicate that progeny of both nitrogen-limited and salt-stressed plants have greater tolerance to those stresses, as demonstrated by their enhanced total biomass compared to progeny of non-stressed control plants (Boyko et al., 2010; Kou et al., 2011). Increased tolerance to nitrogen limitation in rice persisted over two progeny generations (Kou et al., 2011).

In addition to abiotic stresses, biotic stresses such as herbivory can induce heritable, adaptive phenotypic responses. In Raphanus raphanistrum, the seedling offspring of herbivore-damaged plants (or plants treated with jasmonic acid, an elicitor of plant defenses) had measurably increased resistance to herbivory (evidently due to both trichome density and biochemical defenses; see Mechanisms of Transgenerational Response section; Agrawal, 2001, 2002). As a result, Pieris rapae caterpillars that fed on these seedlings grew 20\% less than caterpillars that fed on seedlings of undamaged mother plants (Agrawal et al., 1999), a robust example of transgenerational plant responses likely to influence higherorder community dynamics. Caterpillar herbivory also significantly increased individual seed mass and enhanced early seedling growth in some maternal families, but reduced these traits in other Raphanus families (Agrawal, 2001, 2002). Interestingly, the effects of maternal herbivory on seed mass were as large as the effects of genetic line, and consequently as likely to influence natural selection in this system as inherited genetic variation. Similarly, Mimulus guttatus plants with experimentally damaged leaves (i.e., simulated herbivory) produced offspring with higher densities of defensive leaf trichomes compared to genetically identical offspring of undamaged control plants (Holeski, 2007). Transgenerational responses to herbivory also appear to be adaptive in the colonizing annual Impatiens capensis. Offspring of plants that experienced natural herbivory in the field emerged earlier, grew taller, and had significantly greater biomass than offspring of plants protected from most herbivores (Steets and Ashman, 2010).

Research designed to test plant responses to complex naturalistic stresses can provide insights of direct ecological relevance. For instance, serpentine soils impose at least three distinct environmental challenges to plants: nutrient stress, drought stress, and exposure to high metal concentrations (Dyer et al., 2010). Studies of the invasive grass Aegilops triuncialis identified putatively adaptive transgenerational effects of this edaphic environment on offspring phenology and success (Dyer et al., 2010): offspring of parent $A$. triuncialis plants grown in serpentine soil flowered earlier (which permits reproduction to occur prior to the onset of summer drought) and grew to a larger size (associated with greater reproductive output) when they were grown in low-nutrient soil, compared to offspring of the same genotypes whose parents had been grown in moist loam (Dyer et al., 2010).

Furthermore, distinct aspects of environmental stress may interact to elicit complex transgenerational responses. In P. lanceolata, the ability of seedlings to express an adaptive, compensatory growth response to disturbance (i.e., simulated grazing by severe shoot removal) was influenced by both parental disturbance and parental nutrient stress: offspring growth more than compensated for biomass loss due to disturbance if the mother had been either disturbed and grown in nutrient-rich soil, or not disturbed and grown in nutrient-poor soil (Latzel et al., 2010). Such complex, interacting transgenerational effects are likely to be important in natural plant populations, which encounter concurrent variation in multiple abiotic and biotic environmental factors.

An elegant series of field experiments with the forest-edge herb Campanulastrum americanum has examined the interplay between adaptive transgenerational plasticity and life-history expression in complex natural habitats. When maternal and offspring plants were both grown in either forest light gaps or understory shade, germination fraction and seedling survival were significantly higher, and adult offspring had significantly greater relative leaf areas and produced significantly larger seeds, than "mismatched" combinations of parent and offspring light habitat (Galloway and Etterson, 2007, 2009). Demographic projections indicate that population growth would be three times greater when offspring were grown in the same light environment maternal plants had experienced (a likely scenario given the species' limited seed dispersal range; Galloway and Etterson, 2007). In addition to this evidence for adaptive transgenerational plasticity in offspring growth and reproduction, this system also exemplifies how maternal environment can adaptively alter life-history expression in the offspring generation, an even more dramatic transgenerational response (Galloway, 2005; Galloway and Etterson, 2007, 2009). C. americanum offspring are more likely to express an annual life-history if their maternal parent grew in a forest light gap, where sufficient light is likely available to reproduce within a single season, and a biennial lifehistory if their maternal parent grew in understory shade where a longer growth period is required to successfully reproduce (Galloway and Etterson, 2007). Expression of annual versus biennial life-history schedule was also influenced by maternal flowering time and maternal exposure to herbivory (Galloway and Burgess, 2009; Lin and Galloway, 2010), demonstrating the rich complexity of factors involved in transgenerational responses to natural environments.

Transgenerational responses to complex seasonal conditions also play an important role in life-history expression in Arabidopsis, which is jointly shaped by maternal and offspring environments. In studies by Donohue et al. (2005), seasonal factors that influenced reproductive timing, along with conditions during seed maturation and after dispersal, determined germination timing and offspring life-history schedule. Companion laboratory studies showed that germination timing was highly responsive to individual environmental variables such as temperature, photoperiod, and canopy shade (reviewed in Donohue, 2009). In order to assess the adaptive value of these maternal seasonal effects, Donohue (2009) used a demographic analysis to test how population growth rates would be affected if maternal environment did not influence offspring germination. She found that population growth would be reduced by as much as $30 \%$ if germination (and consequently life-history schedule) were not responsive to maternal environmental conditions (Donohue, 2009). Related studies showed furthermore that transgenerational plasticity for life-history expression can create selective feedbacks that either promote or constrain evolutionary change (Donohue, 2005). 


\section{ADAPTIVE TRANSGENERATIONAL PLASTICITY: A CASE STUDY}

Experiments with annual species in the genus Polygonum (sensu lato) provide a case study of transgenerational plasticity expressed by naturally evolved genotypes exposed to controlled environmental stresses. Field-collected individuals of these primarily selffertilizing species can be cloned or highly inbred to produce replicate, genetically uniform, highly homozygous parent individuals. These replicate parents can be raised in contrasting glasshouse resource treatments (based on the range of environmental conditions in nature) and allowed to produce selfed progeny (singleseeded achenes). These can be germinated in specified seedling environments to precisely assess the effects of parental environment on offspring development in the absence of confounding genetic variation (Sultan, 2000) and of possible (if unlikely) selective effects at the level of gametophytes, gametes, or embryos (Mazer and Gorchov, 1996). Because these Polygonum species are gravity-dispersed, progeny are likely to germinate close to the parent plant, so the likelihood of encountering a similar microsite is high. This experimental system has produced several examples of transgenerational responses to naturalistic resource stresses that enhance seedling success under like stressful conditions, and has revealed variation in these responses among genotypes, closely related species, and even seed architectural positions. These findings are particularly intriguing because resource deprivation was previously assumed to result only in maladaptive reductions in offspring size (Roach and Wulff, 1987). Instead, the Polygonum case study makes clear that the ability to express adaptive transgenerational plasticity is a significant aspect of ecologically important genetic and species diversity (Sultan, 2001; Sultan et al., 2009).

In the initial study, clonal replicates of Polygonum persicaria genotypes raised in very low light produced equally wellprovisioned seeds as plants given full sun, but reduced the mass of carbon-rich pericarp tissue enclosing the seeds by over $40 \%$ (Sultan, 1996). Light-limited parents thus maintained essential offspring provisioning at the cost of reduced longevity in the soil (Sultan, 1996; see also Lacey et al., 1997). Their offspring also produced more shoot tissue relative to root biomass than offspring of plants grown in full sun (Sultan, 1996), a likely pre-adaptation to shade conditions (Salisbury, 1974; Haig and Westoby, 1988). In contrast, clonal replicates of the same parental genotypes raised in nutrient-poor conditions slightly reduced seed provisioning. Despite this reduction, however, the offspring of nutrient-deprived parents increased root allocation to produce (non-significantly) longer root systems than the offspring of genetically identical parents grown in nutrient-rich soil (Sultan, 1996), a transgenerational response that would benefit seedlings in nutrient-poor soil by maximizing root uptake surface for mineral ions (Wulff, 1986a).

A later experiment compared the effects of parental drought stress on seedling development in P. persicaria, which occurs in variably dry to moist sites, and Polygonum hydropiper, a closely related species limited to consistently moist habitats (Sultan et al., 1998, 2009). For several highly inbred genotypes of each species, achenes produced by replicate parents grown in either dry or moist conditions were raised for 21 days in either dry or moist seedling treatments, in a full-factorial split-brood design (Sultan et al., 2009). Because the rapid production of deep, extensive root systems is particularly critical for seedlings in dry soil (Hoffman and Isselstein, 2004; Moles and Westoby, 2006), root growth was monitored carefully. Drought-stressed parent plants of $P$. persicaria produced more well-provisioned seedling offspring that made longer, more rapidly extending root systems in dry soil than the offspring of replicate parents of the same inbred lines that had been given ample water, resulting in significantly greater seedling growth (Sultan et al., 2009; see also Sultan, 1996). The offspring of moist-grown P. persicaria plants also produced slightly (non-significantly) larger seedlings in the moist seedling environment, evidence of an adaptive match between both moist and dry parental and offspring environments (Sultan et al., 2009; see Galloway and Etterson, 2007). In contrast, P. hydropiper plants transmitted a direct, maladaptive effect of parental drought stress to their offspring: in this species, droughtstressed parents simply produced smaller seedlings, with correspondingly slower-extending root systems, that grew less than the offspring of well-watered parents in both dry and moist seedling conditions (Sultan et al., 2009). Seedlings of both species increased root:shoot biomass ratio and specific root length (SRL) when grown in dry soil; these developmental traits were not influenced by parental environment. Seedling phenotypes in these taxa thus reflected both inherited (transgenerational) and immediate responses to moisture environment (Sultan et al., 2009). Note that the combination of these two modes of plasticity resulted in an earlier and more pronounced adaptive response in P. persicaria seedlings than could be achieved via immediate plasticity alone, a crucial benefit of transgenerational effects (see also Agrawal et al., 1999).

Further studies (Herman et al., unpublished data) show that the adaptive effects of drought stress in P. persicaria persist across two generations: the grandchildren of drought-stressed plants were more well-provisioned, grew larger, and produced deeper and more extensive root systems in dry soil than the grandchildren of well-watered plants of the same inbred genetic lines. Interestingly, this effect remained significant even when seedling biomass was removed as a covariate, showing that production of these enhanced root systems is not simply due to greater provisioning, but reflects a specific developmental adjustment likely mediated by hormonal and/or epigenetic effects shaped by natural selection (Sultan et al., 2009). Higher survivorship in dry soil of seedlings produced after one or two generations of drought stress (Herman and Sultan, unpublished data) indicates that these transgenerational effects on development are indeed likely to influence realized fitness in nature, where soil moisture varies spatially and temporally within and among Polygonum microsites (Sultan et al., 1998).

A central insight from this body of work is that transgenerational consequences of resource deprivation in plants are not generalized, passive stress effects. Rather, these are specific developmental responses that vary depending on the resource or combination of resources in question and their precise state(s) (Sultan, 2000; e.g., Sultan, 1996, 2001). These transgenerational responses also vary among naturally evolved genomes: even relatively small samples of Polygonum genotypes reveal significant variation for provisioning, germination, and root length responses to parental drought; germination and achene-mass responses to parental nutrient stress, and developmental effects of parental 
shade (Schmitt et al., 1992). These differences at the genotype level (documented in analyses of variance as significant genotype-byparental environment interaction effects) provide the raw material for continued adaptive evolution of transgenerational response patterns, just as genotype-by-environment effects fuel selective evolution of immediate plasticity patterns (Via and Lande, 1985; Sultan, 2007, 2011).

Surprisingly, transgenerational effects of parental resource stress can also vary among offspring that develop in different architectural positions on the maternal plant. $P$. hydropiper is a species that produces achenes in both axial and terminal inflorescences on each plant. Terminally produced offspring of parents grown in simulated shade expressed dramatically different developmental trajectories than terminal offspring of highly inbred replicate plants given full sun: they produced leaves significantly earlier and in greater numbers, grew taller faster, and produced more than double the biomass by day 21 (Lundgren and Sultan, 2005). However, none of these adaptive transgenerational effects of parental shade on seed provisioning and shoot development were expressed in the axially produced achenes (Lundgren and Sultan, 2005). Although position effects on offspring size are generally interpreted as the result of seed location relative to plant vasculature and source-sink relations (Diggle, 1995; Imbert, 2002), these more complex positional differences in transgenerational response may instead reflect an evolved response to "prioritize" terminal achenes, which have greater dispersal ability (see Imbert and Ronce, 2001; Diggle and Miller, 2004).

As described above, patterns of transgenerational plasticity can also differ dramatically even among very closely related taxa, such as annual Polygonum species within a monophyletic subgroup of the genus. Comparisons among four such species showed significant differences in both the magnitude and direction of effects of drought and nutrient stress on individual achene-mass (Sultan, 2001), seedling biomass, and rooting depth rate (Elmendorf and Sultan, unpublished data). For instance, three of the species adaptively increased seedling SRL and extension rate in response to parental nutrient deprivation compared with offspring of wellnourished parents, but seedlings in a fourth species reduced SRL and reached a soil depth threshold 1.5 days slower than offspring of well-nourished plants in response to the same parental nutrient stress (Elmendorf and Sultan, unpublished data). Species-level differences in the capacity for adaptive transgenerational plasticity demonstrate that these response patterns, like other products of evolution, are shaped by genetic constraints and random forces as well as by natural selection.

\section{MECHANISMS OF TRANSGENERATIONAL RESPONSE}

Plastic responses to environmental stress can be transmitted across plant generations via multiple mechanisms, independently or indeed in the absence of DNA sequence variation. It is well known that environmental challenges to a maternal plant can affect the quantity and composition of starch reserves, mRNAs, proteins, hormones, and other primary and secondary metabolites packaged into seeds (Roach and Wulff, 1987; Leishman et al., 2000; Fenner and Thompson, 2005; Moles and Leishman, 2008), and that these seed resources are critical for both germination and initial seedling growth. Recently, it has become clear that stressful parental environments can also induce epigenetic variation, specifically in DNA methylation patterns, that is associated with changes in ecologically important traits, and that may persist for several- and possibly many - generations (Jablonka and Raz, 2009; Hauser et al., 2011). Differences in the duration of various transgenerational effects may reflect differences in their underlying mechanisms: for instance, provisioning effects are likely to be shorter lived than most DNA methylation marks (Latzel and Klimešová, 2010), both within an individual's life-cycle and across generations. Below we present a brief overview of these various mechanisms, noting that they are neither rigidly separate nor mutually exclusive: more than one mechanism or type of mechanism can jointly influence heritable phenotypes.

\section{TRANSGENERATIONAL PLASTICITY VIA SEED PROVISIONING}

Seed provisioning refers to the carbohydrate, lipid, protein, and mineral nutrient reserves allocated by the maternal plant to the developing seed (Koller, 1972; Srivastava, 2002). These reserves are mobilized in germinating seedlings to produce the initial shoot and root systems that allow for establishment as a functional individual. Seed provisioning is often reduced when maternal plants are deprived of resources such as light or minerals, resulting in diminished early growth rates, seedling size, and competitive ability (Haig and Westoby, 1988; Fenner and Thompson, 2005). In contrast to these maladaptive transgenerational effects, environmentally stressed maternal plants of certain species are able to maintain or even increase seed provisioning (Roach and Wulff, 1987; Schmitt et al., 1992; Sultan, 1996, 2001; Donohue and Schmitt, 1998), an adaptive response that can maximize seedling survival. This head start in growth can provide a crucial advantage at this vulnerable life-history stage, particularly in stressful conditions (Wulff, 1986b; Agrawal et al., 1999; Moles and Westoby, 2006). For instance, well-provisioned offspring can produce more extensive root systems in dry soil, or larger shoot systems under canopy shade (Silvertown, 1984; Wulff, 1986a; Leishman et al., 2000). In natural populations, the adaptive benefit of such enhanced provisioning may be limited in two ways. First, resourcedeprived maternal plants inevitably produce fewer seeds, even if each one is more likely to successfully establish; and second, tradeoffs may exist between increased seed provisioning and decreased persistence in the soil seed bank (Sultan, 1996; Donohue and Schmitt, 1998; Fenner and Thompson, 2005). Hence, transgenerational effects that are mediated via seed provisioning can promote offspring success in stressful conditions, but these benefits will depend on the specific ecological setting.

\section{TRANSGENERATIONAL PLASTICITY VIA mRNAs, PROTEINS, AND HORMONES}

Numerous studies have identified effects of environmental stress on offspring development that are not related to seed provisioning, indicating that other mechanisms commonly mediate this transgenerational aspect of plasticity (e.g., Case et al., 1996; Agrawal, 2001, 2002; Bischoff and Muller-Scharer, 2010; Dyer et al., 2010). As discussed below, seed mass-independent responses to parental stress may be transmitted to offspring via maternally derived proteins and mRNAs or other small RNAs; defensive chemicals or other secondary metabolites; changes in the relative 
concentrations of hormones; and/or environmentally induced epigenetic marks, such as DNA methylation or histone modifications. Note that maternally derived proteins can affect offspring phenotypes via both as regulatory molecules, as described below, and as nutritive elements (see Transgenerational Plasticity via Seed Provisioning section).

Maternally derived mRNAs and proteins play an important role in the regulation of seed dormancy and germination (Donohue, 2009). Rajjou et al. (2004) found that non-dormant A. thaliana seeds can germinate in the absence of post-dispersal transcription, and that there is very little transcriptional activity for the first $16 \mathrm{~h}$ following germination. This remarkable result shows that stored proteins and mRNAs are adequate for germination of nondormant seeds in Arabidopsis. (Transcription-inhibited seeds did germinate more slowly than control seeds, indicating that de novo gene expression is important in regulating germination rate.) Noting that environmental stress can alter many aspects of maternal gene expression, the authors suggest that translation of maternally derived mRNAs may facilitate adaptive growth responses for seeds germinating under stressful conditions (Rajjou et al., 2004).

Maternal environmental stress can also alter seed hormone content and embryonic sensitivity to hormones. For example, experimentally shaded Amaranthus palmeri plants increased the abscisic acid (ABA) content of their seeds by 44\% (Jha et al., 2010), and maternal drought stress-induced changes in both seed ABA content and embryo sensitivity to ABA in Sorghum bicolor (Arnold et al., 1991). Because ABA is a central regulator of plant growth throughout the life-cycle, especially under stressful conditions (Holdsworth et al., 2008a,b; Cutler et al., 2010; Peleg and Blumwald, 2011), these results suggest that such hormone adjustments are a likely mechanism for transgenerational environmental effects on offspring growth and development (Sultan, 1996; Baskin and Baskin, 1998). However, maternal environmental effects on seed hormone content, and the realized impact of such effects on seedling development compared with other factors, are not yet well known. For instance, seed germination is influenced by embryonic gene expression and levels of tissue ABA (Kucera et al., 2005; Donohue, 2009) as well as maternal mRNAs and proteins (Rajjou et al., 2004), but their relative importance as regulators of ecologically appropriate germination behavior is unclear (Donohue, 2009). Although it is challenging to study hormone levels in seed tissues, this potentially important mode of adaptive transgenerational stress response merits further study.

\section{DNA METHYLATION AND HISTONE MODIFICATIONS}

DNA methylation marks tend to silence gene expression by forming densely compact chromatin; these marks are both environmentally sensitive and heritable over multiple (i.e., $\geq 8$ ) generations (Johannes et al., 2009; Reinders et al., 2009; comprehensively reviewed by Jablonka and Raz, 2009; Hauser et al., 2011). Accordingly, DNA methylation (and possibly other epigenetic mechanisms) is likely to play an important role in regulating transgenerational effects of environmental stress (Kalisz and Purugganan, 2004; Grant-Downton and Dickinson, 2006; Boyko and Kovalchuk, 2011). Recent studies of epigenetic recombinant inbred lines (epiRILs) in Arabidopsis provide important insights to these inherited effects on gene expression. These epiRILs were derived from two isogenic parental lines: one homozygous for a mutation that causes a deficiency in DNA methylation, and the other wild type. As a result, epiRILs have segregating DNA methylation variation, but zero DNA sequence variation (Johannes et al., 2009; Reinders et al., 2009; Teixeira et al., 2009), allowing for the study of quantitative epigenetic variation in plant traits without confounding effects of genetic variation (Richards, 2009). Several important conclusions emerge from the work on epiRILs thus far: (1) stable inheritance of DNA methylation variation can occur at a large number of sites within the genome (for instance, Reinders et al. (2009) found 6532 of these sites in one epiRIL); (2) DNA methylation epialleles have a range of transgenerational stabilities; and (3) such variation often has substantial effects on ecologically important, fitness-related traits such as reproductive phenology, germination timing, plant height, and pathogen resistance (Johannes et al., 2009; Reinders et al., 2009; Teixeira et al., 2009).

A wide variety of naturally occurring plant environmental stresses can induce DNA methylation changes, including drought (Labra et al., 2002; Boyko et al., 2010; Wang et al., 2011), flooding (Boyko et al., 2010), nutrient limitation (Boyko et al., 2010; Kou et al., 2011), temperature shock (Boyko et al., 2010), pathogen infection (Boyko et al., 2007; Kathiria et al., 2010), high salinity (Boyko et al., 2010; Verhoeven et al., 2010), heavy metal exposure (Aina et al., 2004), UV radiation (Boyko et al., 2010), and possibly herbivory (Herrera and Bazaga, 2011; Scoville et al., 2011). However, despite intense interest in the subject, relatively few studies have focused on potentially adaptive effects of DNA methylation changes induced by such ecologically relevant environmental stresses - i.e., on DNA methylation as a mechanism of adaptive transgenerational stress response. In one case, Boyko et al. (2010) found that progeny of salt-stressed Arabidopsis parents had increased tolerance to salt stress. This adaptive response correlated with inheritance of stress-induced DNA methylation marks, as well as increased frequency of somatic homologous recombination. (Note that heritable changes in homologous recombination rate may not be a general stress response in Arabidopsis, as shown by the weak and inconsistent effects of various chemical toxins on progeny recombination rates in two transgenic lines; Pecinka et al., 2009). Further study showed that this response depended on the action of Dicer-like proteins that operate in the small RNA pathway (Boyko et al., 2010). Infection with tobacco mosaic virus (TMV) also caused heritable changes in DNA methylation (again associated with increased recombination frequency) and greater pathogen resistance in progeny, possibly due to the higher constitutive and induced levels of PATHOGENESIS-RELATED GENE1 in progeny of TMV-infected plants (Kathiria et al., 2010). These mechanistic studies are among the first to show that environmentally induced DNA methylation changes are associated with adaptive effects on offspring. Much further study is needed, however, because it is still unclear exactly what signal is transmitted across generations: DNA methylation marks might escape resetting in the germline, or they might be re-instated by the action of transmitted small RNAs or histone modifications (Hauser et al., 2011; Paszkowski and Grossniklaus, 2011).

Verhoeven et al. (2010) focused on the inheritance of stressinduced DNA methylation variation in apomictic dandelions 
(Taraxacum officinale), a naturally evolved, non-model system. They exposed genetically identical parent dandelion plants to a variety of environmental stress treatments, and then analyzed changes in DNA methylation that were transmitted to untreated progeny (Verhoeven et al., 2010). Salicylic acid, jasmonic acid, salt stress, and nutrient limitation each induced a considerable number of DNA methylation changes relative to controls, with 74-92\% of these changes transmitted to progeny (salicylic acid induced a greater number of heritable changes than the other stresses). Importantly, many of the methylation changes induced by salicylic acid (simulated pathogen attack) were targeted to specific areas of the genome. This divergence in DNA methylation pattern suggests that methylation changes were directed to specific stress response genes (Verhoeven et al., 2010). A key contribution of this study is that it demonstrates, in a naturally evolved taxon, both the environmental sensitivity of DNA methylation and the potential of DNA methylation to operate as an independent inheritance system. However, because only one genotype was studied for a single offspring generation, and because effects on offspring phenotype were not reported, the ecological and evolutionary relevance of these findings remains to be determined (Verhoeven et al., 2010).

Post-translational modifications of histone proteins can also affect gene expression by altering chromatin structure, and studies in yeast (Grewal et al., 1998), mice (Blewitt et al., 2006), and Arabidopsis (Lang-Mladek et al., 2010) suggest that these modifications can be transferred across generations. Although more than 100 different histone modifications have been identified, the consequences of the vast majority of these modifications are unknown (Bernstein et al., 2007), and it is not yet clear to what extent these changes act independently of DNA methylation effects. One study in Arabidopsis found that heat stress and UV-B exposure each induced heritable changes in gene expression that correlated with histone $\mathrm{H} 3$ deacetylation in the absence of DNA methylation changes (Lang-Mladek et al., 2010). This effect on gene expression persisted for two progeny generations, but occurred only in small groups of cells within the plant.

\section{JOINT EFFECTS OF TRANSGENERATIONAL PLASTICITY MECHANISMS}

As noted previously, two or more modes of transgenerational stress response may act in combination to influence offspring phenotypes. For example, Agrawal and coworkers observed both seed mass-dependent and seed mass-independent responses to maternal herbivory in wild radish, $R$. raphanistrum (Agrawal et al., 1999; Agrawal, 2001, 2002). (Seed mass is generally a reliable proxy for seed provisioning; Moles and Leishman, 2008, but see Lacey et al., 1997). Caterpillar herbivory significantly increased the mass of individual seeds produced (see preceding section), but also significantly enhanced seedling growth and leaf trichome density independently of seed mass effects (Agrawal, 2001, 2002). Although the mechanisms of these non-provisioning effects have not been determined with certainty, there is some evidence that allocation of defensive chemicals and/or defense-inducing hormones to seeds may be involved (Agrawal, 2002; epigenetic mechanisms are a further possibility, but have not been investigated in this system). Scoville et al. (2011) linked increased trichome density in progeny of maternal M. guttatus plants subjected to simulated herbivory to epigenetically inherited changes in the expression of a
MYB transcription factor. Preliminary evidence suggests that DNA methylation is likely involved in transmitting the high trichome density phenotype across generations (Scoville et al., 2011). These results illustrate how a single environmental stress can induce multiple physiological and epigenetic changes that together enhance offspring performance.

A second way that transgenerational mechanisms can interact is via hormonal effects on epigenetic marks. Hormones can influence gene expression in response to stress via effects on both histone modifications and DNA methylation (Chinnusamy and Zhu, 2009). Studies in Arabidopsis and rice have shown that a variety of environmental stresses and resulting hormone signals influence the expression of histone deacetylases that downregulate gene expression (Zhou et al., 2005; Fu et al., 2007; Wu et al., 2008). For example, ABA reduced the expression of the histone deacetylase AtHD2C in Arabidopsis, causing a decrease in stomatal conductance, which is a critical response to drought stress (Sridha and $\mathrm{Wu}, 2006)$. Hormone-mediated changes in histone modifications may also affect DNA methylation via the RNA-directed DNA methylation (RdDM) pathway. The histone deacetylase HDA6 is both required for the jasmonate response and involved in RdDM, suggesting a potential role for jasmonate in regulation of DNA methylation via effects on histone acetylation (Aufsatz et al., 2002; Probst et al., 2004; Wu et al., 2008). Any constituent of these environmentally sensitive and interacting pathways - hormone, RNA, histone modification, or DNA methylation - could be transmitted across generations, forming the heritable basis for transgenerational plasticity (Jablonka and Raz, 2009; Hauser et al., 2011). Investigating these interacting pathways offers an exciting research direction that promises to link signal transduction of environmental cues to potentially heritable changes in phenotypic expression.

\section{CONCLUSION: ECOLOGICAL AND EVOLUTIONARY IMPLICATIONS}

Although a great deal remains to be learned about the ability to express adaptive transgenerational plasticity in diverse plant taxa, populations, and genotypes in response to various abiotic and biotic environmental factors, and about the precise mechanisms, nature, and duration of those responses, existing knowledge leads to a fundamental insight: Because this mode of individual plasticity gives rise to phenotypes that are both adaptive to the conditions that induce them and inherited, it can influence the ecological distribution of plant populations as well as their evolutionary trajectories.

With respect to ecological distribution, taxa capable of such plasticity may be more likely to establish and maintain populations in variably or consistently stressful habitats, because offspring will be specifically pre-adapted to withstand the low resource levels or other stresses experienced by their parent(s). As noted above, transgenerational plasticity can allow offspring individuals to express a more extreme adaptive phenotype early in life, without undergoing the developmental lag time required for response to the immediate environment (Sultan, 1996; Agrawal et al., 1999; Sultan et al., 2009). Because the great majority of plant mortality occurs at the seedling stage (Fenner and Thompson, 2005; Moles and Leishman, 2008), this enhanced ecological tolerance is likely 
to obtain even in the case of provisioning effects that are expressed only during initial life-cycle stages, or that persist for only a single generation. Indeed, transgenerational effects that persist for one or few generations can substantially influence both phenotypic distributions and population growth rates (Galloway and Etterson, 2007; Donohue, 2009; Inchausti and Ginzburg, 2009).

Existing repertoires of transgenerational plasticity may also allow certain taxa to better tolerate novel stressful environments, such as the global temperature and moisture changes predicted to arise very rapidly due to human activities. This may be of particular benefit in long-lived woody and perennial taxa, in which adaptation by selective evolution is unlikely to keep pace with such rapid environmental changes. Note that these same ecological effects are also likely to promote the spread of invasive plants, which may more successfully withstand environmental stresses encountered in a new, introduced range, and more quickly colonize its diverse habitats, by virtue of transgenerational pre-adaptations. Moreover, transgenerational plasticity may not only hasten the spread of invasive taxa compared with the slower process of evolutionary adaptation, it may allow for ecological spread in cases where invasive populations lack the genetic potential for such evolutionary change (Hollingsworth and Bailey, 2000; Dlugosch and Parker, 2008; Dyer et al., 2010).

Evolutionary consequences of transgenerational responses are an equally promising area for further investigation. Such responses depart from standard evolutionary scenarios in two key ways (Jablonka and Raz, 2009; Verhoeven et al., 2010). First, transgenerational plasticity gives rise to adaptive heritable variation precisely when it is required in a population, in contrast to randomly occurring genetic variation (Verhoeven et al., 2010). Second, a given environmental stress can induce the same adaptive phenotype in numerous offspring individuals in a population at the same time, again in contrast to a new phenotype arising due to mutation in one or few individuals. In consequence, populations can undergo rapid and wholesale phenotypic adaptation in the absence of allelic (DNA sequence) frequency change (Jablonka and Raz, 2009). Indeed, adaptive adjustments due to transgenerational plasticity may buffer a population against such evolutionary change by permitting existing genotypes to maintain fitness in the face of environmental challenges (Sultan, 2000).

To some extent, the inheritance mechanisms and relative persistence of these environmental effects will shape their evolu-

\section{REFERENCES}

Agrawal, A. (2001). Transgenerational consequences of plant responses to herbivory: an adaptive maternal effect? Am. Nat. 157, 555-569.

Agrawal, A. (2002). Herbivory and maternal effects: mechanisms and consequences of transgenerational induced plant resistance. Ecology 83, 3408-3415.

Agrawal, A., Laforsch, C., and Tollrian, R. (1999). Transgenerational induction of defences in animals and plants. Nature 401, 60-63.

Aina, R., Sgorbati, S., Santagostino, A., Labra, M., Ghiani, A., and Citterio, S. (2004). Specific hypomethylation

tionary impact. For instance, because epialleles (such as alternative patterns of DNA methylation) induced by environmental stress influence individual fitness, in cases where they persist across multiple generations, adaptive evolution could proceed by selection of such epigenetic variants alone. As noted above, such change could take place much faster than standard evolution by allelic substitution (Jablonka and Lamb, 1995; Richards, 2006; Bossdorf et al., 2008). Selection of epialleles may also influence evolution by shifting the relative frequencies of correlated genetic variants (Jablonka and Raz, 2009). In contrast, short-lived effects on provisioning (or transient epigenetic effects) may primarily serve to buffer plant populations from selective change by allowing individuals to express similar, adaptive phenotypes.

A central goal for future transgenerational plasticity research is to integrate studies of inheritance mechanisms with research designed to incorporate ecological and evolutionary realism; e.g., studies in naturally evolved systems that test response to fieldbased environments. For instance, transgenerational plasticity experiments could be combined with a methylation-sensitive AFLP (MS-AFLP) assay, to test for the involvement of DNA methylation in the production and maintenance of environmentally induced adaptive, heritable phenotypes. As in recent studies of epigenetic variation in natural plant populations (Herrera and Bazaga, 2010, 2011; discussed in Richards et al., 2010; Bossdorf and Zhang, 2011), population genetic analyses could be employed to assess epigenetic differentiation among treatment groups and taxa, and to test for statistical associations between specific epialleles and adaptive phenotypes. Interdisciplinary studies of transgenerational plasticity that focus jointly on the mechanisms of transmission and on the adaptive (developmental and fitness) consequences of these induced responses will be of particular value in understanding this intriguing aspect of plant plasticity.

\section{ACKNOWLEDGMENTS}

Research from the laboratory of Sonia E. Sultan was funded by the U.S. National Science Foundation, the Mathers Charitable Foundation, the Mellon Foundation Program in Conservation and the Environment, the University of California, Davis Center for Population Biology, and Wesleyan University, with student support from the Howard Hughes Medical Foundation.

Baskin, J. M., and Baskin, C. C. (1998). Seeds. Ecology, Biogeography and Evolution of Dormancy and Germination. San Diego: Academic Press.

Bernstein, B. E., Meissner, A., and Lander, E. S. (2007). The mammalian epigenome. Cell 128, 669-681.

Bischoff, A., and Muller-Scharer, $\mathrm{H}$. (2010). Testing population differentiation in plant species-how important are environmental maternal effects. Oikos 119, 445-454.

Blewitt, M., Vickaryous, N., Paldi, A., Koseki, H., and Whitelaw, E. (2006). Dynamic reprogramming of DNA methylation at an epigenetically sensitive allele in mice.
PLoS Genet. 2, e49. doi:10.1371/journal.pgen.0020049

Bossdorf, O., Richards, C. L., and Pigliucci, M. (2008). Epigenetics for ecologists. Ecol. Lett. 11, 106-115.

Bossdorf, O., and Zhang, Y. (2011). A truly ecological epigenetics study. Mol. Ecol. 20, 1572-1574.

Boyko, A., Blevins, T., Yao, Y. L., Golubov, A., Bilichak, A., Ilnytskyy, Y., Hollander, J., Meins, F., and Kovalchuk, I. (2010). Transgenerational adaptation of Arabidopsis to stress requires DNA methylation and the function of dicerlike proteins. PLoS ONE 5, e9514. doi:10.1371/journal.pone.0009514 
Boyko, A., Kathiria, P., Zemp, F. J., Yao, Y., Pogribny, I., and Kovalchuk, I. (2007). Transgenerational changes in the genome stability and methylation in pathogen-infected plants (virus-induced plant genome instability). Nucleic Acids Res. 35, 1714-1725.

Boyko, A., and Kovalchuk, I. (2011). Genome instability and epigenetic modification - heritable responses to environmental stress? Curr. Opin. Plant Biol. 14, 260-266.

Case, A., Lacey, E., and Hopkins, R. (1996). Parental effects in Plantago lanceolata L. II. Manipulation of grandparental temperature and parental flowering time. Heredity 76 , 287-295.

Chinnusamy, V., and Zhu, J.-K. (2009). Epigenetic regulation of stress responses in plants. Curr. Opin. Plant Biol. 12, 133-139.

Cutler, S. R., Rodriguez, P. L., Finkelstein, R. R., and Abrams, S. R. (2010). Abscisic acid: emergence of a core signaling network. Annu. Rev. Plant Biol. 61, 651-679.

Danchin, E., Charmantier, A., Champagne, F. A., Mesoudi, A., Pujol, B., and Blanchet, S. (2011). Beyond DNA: integrating inclusive inheritance into an extended theory of evolution. Nat. Rev. Genet. 12, 475-486.

Diggle, P. K. (1995). Architectural effects and the interpretation of patterns of fruit and seed development. Annu. Rev. Ecol. Syst. 26, 531-552.

Diggle, P. K., Abrahamson, N. J., Baker, R. L., Barnes, M. G., Koontz, T. L., Lay, C. R., Medeiros, J. S., Murgel, J. L., Shaner, M. G. M., Simpson, H. L., Wu, C. C., and Marshall, D. L. (2010). Dynamics of maternal and paternal effects on embryo and seed development in wild radish (Raphanus sativus). Ann. Bot. 106, 309-319.

Diggle, P. K., and Miller, J. S. (2004). Architectural effects mimic floral sexual dimorphism in Solanum (Solanaceae). Am. J. Bot. 91, 2030-2040.

Dlugosch, K. M., and Parker, I. M. (2008). Founding events in species invasions: genetic variation, adaptive evolution, and the role of multiple introductions. Mol. Ecol. 17, 431-449.

Donohue, K. (2005). Niche construction through phenological plasticity: life history dynamics and ecological consequences. New Phytol. 166, 83-92.

Donohue, K., Dorn, L., Griffith, C., Kim, E., Aguilera, A., Polisetty, C. R., and Schmitt, J. (2005). Environmental and genetic influences on the germination of Arabidopsis thaliana in the field. Evolution 59, 740-757.

Donohue, K. (2009). Completing the cycle: maternal effects as the missing link in plant life histories. Philos. Trans. R. Soc. Lond. B Biol. Sci. 364, 1059-1074.

Donohue, K., and Schmitt, J. (1998). "Maternal environmental effects in plants: adaptive plasticity?" in Maternal Effects as Adaptations, eds T. Mousseau and C. W. Fox (New York: Oxford University Press), 137-158.

Dyer, A. R., Brown, C. S., Espeland, E. K., Mckay, J. K., Meimberg, H., and Rice, K. J. (2010). The role of adaptive trans-generational plasticity in biological invasions of plants. Evol. Appl. 3, 179-192.

Falconer, D. S. (1981). Introduction to Quantitative Genetics. London: Longman.

Fenner, M., and Thompson, K. (2005). The Ecology of Seeds. Cambridge: Cambridge University Press.

Fu, W., Wu, K., and Duan, J. (2007). Sequence and expression analysis of histone deacetylases in rice. Biochem. Biophys. Res. Commun. 356, 843-850.

Galloway, L. F. (2005). Maternal effects provide phenotypic adaptation to local environmental conditions. New Phytol. 166, 93-99.

Galloway, L. F., and Burgess, K. (2009). Manipulation of flowering time: phenological integration and maternal effects. Ecology 90, 2139-2148.

Galloway, L. F., and Etterson, J. R. (2007). Transgenerational plasticity is adaptive in the wild. Science 318, 1134-1136.

Galloway, L. F., and Etterson, J. R. (2009). Plasticity to canopy shade in a monocarpic herb: within- and between- generation effects. New Phytol. 182, 1003-1012.

Grant-Downton, R., and Dickinson, H. (2005). Epigenetics and its implications for plant biology. 1. The epigenetic network in plants. Ann. Bot. 96, 1143-1164.

Grant-Downton, R., and Dickinson, H. (2006). Epigenetics and its implications for plant biology. 2. The "epigenetic epiphany": epigenetics, evolution and beyond. Ann. Bot. 97, 11-27.

Grewal, S. I., Bonaduce, M. J., and Klar, A. J. (1998). Histone deacetylase homologs regulate epigenetic inheritance of transcriptional silencing and chromosome segregation in fission yeast. Genetics 150, 563-576.

Haig, D., and Westoby, M. (1988). "Inclusive fitness, seed resources, and maternal care," in Plant Reproductive Ecology, eds J. Lovett-Doust and L.
Lovett-Doust (Oxford: Oxford University Press), 60-79.

Hauser, M. T., Aufsatz, W., Jonak, C., and Luschnig, C. (2011) Transgenerational epigenetic inheritance in plants. Biochim. Biophys. Acta 1809, 459-468.

Henderson, I., and Jacobsen, S. (2007) Epigenetic inheritance in plants. Nature 447, 418-424.

Herrera, C. M., and Bazaga, P. (2010). Epigenetic differentiation and relationship to adaptive genetic divergence in discrete populations of the violet Viola cazorlensis. New Phytol. 187, 867-876.

Herrera, C. M., and Bazaga, P. (2011). Untangling individual variation in natural populations: ecological, genetic and epigenetic correlates of long term inequality in herbivory. Mol. Ecol. 20, 1675-1688.

Hoffman, M., and Isselstein, J. (2004) Effects of drought and competition by a ryegrass sward on the seedling growth of a range of grassland species. J. Agron. Crop Sci. 190, 277-286.

Holeski, L. M. (2007). Within and between generation phenotypic plasticity in trichome density of Mimulus guttatus. J. Evol. Biol. 20, 2092-2100.

Holdsworth, M. J., Bentsink, L., and Soppe, W. J. (2008a). Molecular networks regulating Arabidopsis seed maturation, after-ripening, dormancy and germination. New Phytol. 179, 33-54.

Holdsworth, M. J., Finch-Savage, W. E. Grappin, P., and Job, D. (2008b). Post-genomics dissection of seed dormancy and germination. Trends Plant Sci. 13, 7-13.

Hollingsworth, M. L., and Bailey, J. P. (2000). Evidence for massive clonal growth in the invasive weed Fallopia japonica (Japanese Knotweed). Bot. J. Linn. Soc. 133, 463-472.

Imbert, E. (2002). Ecological consequences and ontogeny of seed heteromorphism. Perspect. Plant Ecol. Evol. Syst. 5, 13-36.

Imbert, E., and Ronce, O. (2001). Phenotypic plasticity for dispersal ability in the seed heteromorphic Crepis sancta (Asteraceae). Oikos 93, 126-134.

Inchausti, P., and Ginzburg, L. R. (2009). Maternal effects mechanism of population cycling: a formidable competitor to the traditional predator-prey view. Philos. Trans. R. Soc. Lond. B Biol. Sci. 364 1117-1124.

Jablonka, E., and Lamb, M. J. (1995). Epigenetic Inheritance and Evolution: The Lamarckian Dimension. Oxford, NY: Oxford University Press.
Jablonka, E., and Raz, G. (2009). Transgenerational epigenetic inheritance: prevalence, mechanisms, and implications for the study of heredity and evolution. Q. Rev. Biol. 84, 131-176.

Jha, P., Norsworthy, J. K., Riley, M. B., and Bridges, W. (2010). Shade and plant location effects on germination and hormone content of palmer amaranth (Amaranthus palmeri) seed. Weed Sci. 58, 16-21.

Johannes, F., Porcher, E., Teixeira, F., Saliba-Colombani, V., Simon, M., Agier, N., Bulski, A., Albuisson, J., Fabiana, H., Audigier, P., Bouchez, D., Dillmann, C., Guerche, P., Hospital, F., and Colot, V. (2009) Assessing the impact of transgenerational epigenetic variation on complex traits. PLoS Genet. 5, e1000530. doi:10.1371/journal.pgen.1000530

Kalisz, S., and Purugganan, M. D. (2004). Epialleles via DNA methylation: consequences for plant evolution. Trends Ecol. Evol. (Amst.) 19, 309-314.

Kathiria, P., Sidler, C., Golubov, A., Kalischuk, M., Kawchuk, L. M. and Kovalchuk, I. (2010). Tobacco mosaic virus infection results in an increase in recombination frequency and resistance to viral, bacterial, and fungal pathogens in the progeny of infected tobacco plants. Plant Physiol. 153, 1859-1870.

Koller, D. (1972). "Environmental control of seed germination," in Seed Biology, ed. T. T. Kozlowski (New York: Academic Press), 2-102.

Kou, H. P., Li, Y., Song, X. X., Ou, X. F., Xing, S. C., Ma, J., Liu, B., and Von Wettstein, D. (2011). Heritable alteration in DNA methylation induced by nitrogen-deficiency stress accompanies enhanced tolerance by progenies to the stress in rice (Oryza sativa L.). J. Plant Physiol. 168, 1685-1693.

Kucera, B., Cohn, M. A., and LeubnerMetzger, G. (2005). Plant hormone interactions during seed dormancy release and germination. Seed Sci. Res. 15, 281-307.

Labra, M., Ghiani, A., Citterio, S., Sgorbati, S., Sala, F., Vannini, C., Ruffini Castiglione, M., and Bracale, M. (2002). Analysis of cytosine methylation pattern in response to water deficit in pea root tips. Plant Biol. 4 , 694-699.

Lacey, E., Smith, S., and Case, A. (1997). Parental effects on seed mass: seed coat but not embryo/endosperm effects. Am. J. Bot. 84, 1617-1620.

Lacey, E. P. (1996). Parental effects in Plantago lanceolata L.I. A growth chamber experiment to examine pre- and postzygotic temperature effects. Evolution 50, 865-878. 
Lang-Mladek, C., Popova, O., Kiok, K., Berlinger, M., Rakic, B., Aufsatz, W., Jonak, C., Hauser, M.-T., and Luschnig, C. (2010). Transgenerational inheritance and resetting of stress-induced loss of epigenetic gene silencing in Arabidopsis. Mol. Plant 3, 594-602.

Latzel, V., and Klimešová, J. (2010). Transgenerational plasticity in clonal plants. Evol. Ecol. 24, 1537-1543.

Latzel, V., Klimesova, J., Hajek, T., Gomez, S., and Smilauer, P. (2010). Maternal effects alter progeny's response to disturbance and nutrients in two Plantago species. Oikos 119, 1700-1710.

Leishman, M. R., Wright, I. J., Moles, A. T., and Westoby, M. (2000). "The evolutionary ecology of seed size," in Seeds: The Ecology of Regeneration in Plant Communities, ed. M. Fenner (Wallingford: CAB International), 31-57.

Lin, S. M., and Galloway, L. F. (2010). Environmental context determines within- and potential betweengeneration consequences of herbivory. Oecologia 163, 911-920.

Lundgren, M., and Sultan, S. E. (2005). Seedling expression of crossgenerational plasticity depends on reproductive architecture. Am. J. Bot. 92, 377-381.

Mazer, S., and Gorchov, D. (1996). Parental effects on progeny phenotype in plants: distinguishing genetic and environmental causes. Evolution 50, 44-53.

Moles, A., and Westoby, M. (2006). Seed size and plant strategy across the whole life cycle. Oikos 113, 91-105.

Moles, A. T., and Leishman, M. R. (2008). "The seedling as part of a plant's life history strategy," in Seedling Ecology and Evolution, eds M. A. Leck, V. T. Parker, and R. L. Simpson (New York: Cambridge University Press), 217-238.

Mousseau, T. A., and Fox, C. W. (1998). Maternal Effects as Adaptations. New York: Oxford University Press.

Mousseau, T., Uller, T., Wapstra, E., and Badyaev, A. V. (2009). Evolution of maternal effects: past and present. Philos. Trans. R. Soc. Lond. B Biol. Sci. 364, 1035-1038.

Paszkowski, J., and Grossniklaus, U. (2011). Selected aspects of transgenerational epigenetic inheritance and resetting in plants. Curr. Opin. Plant Biol. 14, 195-203.

Pecinka, A., Rosa, M., Schikora, A., Berlinger, M., Hirt, H., Luschnig, C., and Scheid, O. M. (2009). Transgenerational stress memory is not a general response in Arabidopsis. PLoS ONE 4, e5202. doi:10.1371/journal.pone.0005202

Peleg, Z., and Blumwald, E. (2011). Hormone balance and abiotic stress tolerance in crop plants. Curr. Opin. Plant Biol. 14, 290-295.

Probst, A. V., Fagard, M., Proux, F., Mourrain, P., Boutet, S., Earley, K., Lawrence, R. J., Pikaard, C. S., Murfett, J., Furner, I., Vaucheret, H., and Scheid, O. M. (2004). Arabidopsis histone deacetylase HDA6 is required for maintenance of transcriptional gene silencing and determines nuclear organization of rDNA repeats. Plant Cell 16, 1021-1034.

Rajjou, L., Gallardo, K., Debeaujon, I., Vandekerckhove, J., Job, C., and Job, D. (2004). The effect of alphaamanitin on the Arabidopsis seed proteome highlights the distinct roles of stored and neosynthesized mRNAs during germination. Plant Physiol. 134, 1598-1613.

Reinders, J., Wulff, B. B., Mirouze, M., Mari-Ordonez, A., Dapp, M., Rozhon, W., Bucher, E., Theiler, G., and Paszkowski, J. (2009). Compromised stability of DNA methylation and transposon immobilization in mosaic Arabidopsis epigenomes. Genes Dev. 23, 939-950.

Richards, C. L., Bossdorf, O., and Verhoeven, K. J. F. (2010). Understanding natural epigenetic variation. New Phytol. 187, 562-564.

Richards, E. (2009). Quantitative epigenetics: DNA sequence variation need not apply. Genes Dev. 23, 1601-1605.

Richards, E. J. (2006). Inherited epigenetic variation - revisiting soft inheritance. Nat. Rev. Genet. 7, 395-401.

Roach, D., and Wulff, R. (1987). Maternal effects in plants. Annu. Rev. Ecol. Syst. 18, 209-235.

Rossiter, M. (1996). Incidence and consequences of inherited environmental effects. Annu. Rev. Ecol. Syst. 27, 451-476.

Salisbury, E. J. (1974). Seed size and mass in relation to environment. Philos. Trans. R. Soc. Lond. B Biol. Sci. 186, 83-88.

Schmitt, J., Niles, J., and Wulff, R. (1992). Norms of reaction of seed traits to maternal environments in Plantago lanceolata. Am. Nat. 139, 451-466.

Scoville, A., Barnett, L., Bodbyl Roels, S., Kelly, J. K., and Hileman, L. C. (2011). Differential regulation of a
MYB transcription factor is correlated with transgenerational epigenetic inheritance of trichome density in Mimulus guttatus. New Phytol. 191, 251-263.

Silvertown, J. W. (1984). Phenotypic variety in seed germination behavior: the ontogeny and evolution of somatic polymorphism in seeds. Am. Nat. 124, 1-16.

Sridha, S., and Wu, K. (2006). Identification of AtHD2C as a novel regulator of abscisic acid responses in Arabidopsis. Plant J. 46, 124-133.

Srivastava, L. M. (2002). Plant Growth and Development. San Diego: Academic Press.

Steets, J. A., and Ashman, T. L. (2010). Maternal effects of herbivory in Impatiens capensis. Int. J. Plant Sci. 171, 509-518.

Sultan, S. (2011). "Evolutionary implications of individual plasticity," in Transformations of Lamarckism: from Subtle Fluids to Molecular Biology, eds S. Gissis and E. Jablonka (Cambridge: MIT Press), 193-204.

Sultan, S. E. (1996). Phenotypic plasticity for offspring traits in Polygonum persicaria. Ecology 77, 1791-1807.

Sultan, S. E. (2000). Phenotypic plasticity for plant development, function and life history. Trends Plant Sci. 5 , 537-542.

Sultan, S. E. (2001). Phenotypic plasticity for fitness components in Polygonum species of contrasting ecological breadth. Ecology 82, 328-343.

Sultan, S. E. (2007). Development in context: the timely emergence of eco-devo. Trends Ecol. Evol. (Amst.) 22, 575-582.

Sultan, S. E., Barton, K., and Wilczek, A M. (2009). Contrasting patterns of transgenerational plasticity in ecologically distinct congeners. Ecology 90, 1831-1839.

Sultan, S. E., Wilczek, A., Hann, S. and Brosi, B. (1998). Contrasting ecological breadth of co-occurring annual Polygonum species. J. Ecol. 86, 363-383.

Teixeira, F. K., Heredia, F., Sarazin, A. Roudier, F., Boccara, M., Ciaudo, C. Cruaud, C., Poulain, J., Berdasco, M., Fraga, M. F., Voinnet, O., Wincker, P., Esteller, M., and Colot, V. (2009). A role for RNAi in the selective correction of DNA methylation defects. Science 323, 1600-1604.

Verhoeven, K. J. F., Jansen, J. J., Van Dijk, P. J., and Biere, A. (2010). Stressinduced DNA methylation changes and their heritability in asexual dandelions. New Phytol. 185, 1108-1118.
Via, S., and Lande, R. (1985). Genotypeenvironment interaction and the evolution of phenotypic plasticity. Evolution 39, 505-522.

Wang, W.-S., Pan, Y.-J., Zhao, X.-Q., Dwivedi, D., Zhu, L.-H., Ali, J., Fu, B.-Y., and Li, Z.-K. (2011). Droughtinduced site-specific DNA methylation and its association with drought tolerance in rice (Oryza sativa L.). J. Exp. Bot. 62, 1951-1960.

Whittle, C., Otto, S., Johnston, M., and Krochko, J. (2009). Adaptive epigenetic memory of ancestral temperature regime in Arabidopsis thaliana. Botany 87, 650-657.

Wu, K., Zhang, L., Zhou, C., Yu, C. W., and Chaikam, V. (2008). HDA6 is required for jasmonate response, senescence and flowering in Arabidopsis. J. Exp. Bot. 59, 225-234.

Wulff, R. (1986a). Seed size variation in Desmodium paniculatum. II. Effects on seedling growth and physiological performance. J. Ecol. 74, 99-114.

Wulff, R. (1986b). Seed Size variation in Desmodium paniculatum. III. Effects on reproductive yield and competitive ability. J. Ecol. 74, 115-121.

Zhou, C. H., Zhang, L., Duan, J., Miki, B., and Wu, K. Q. (2005). Histone deacetylase19 is involved in jasmonic acid and ethylene signaling of pathogen response in Arabidopsis. Plant Cell 17, 1196-1204.

Conflict of Interest Statement: The authors declare that the research was conducted in the absence of any commercial or financial relationships that could be construed as a potential conflict of interest.

Received: 07 November 2011; accepted: 07 December 2011; published online: 27 December 2011.

Citation: Herman JJ and Sultan SE (2011) Adaptive transgenerational plasticity in plants: case studies, mechanisms, and implications for natural populations. Front. Plant Sci. 2:102. doi: 10.3389/fpls.2011.00102

This article was submitted to Frontiers in Plant Genetics and Genomics, a specialty of Frontiers in Plant Science. Copyright (c) 2011 Herman and Sultan. This is an open-access article distributed under the terms of the Creative Commons Attribution Non Commercial License, which permits non-commercial use, distribution, and reproduction in other forums, provided the original authors and source are credited. 